\title{
Brincante: 0 encontro do popular e do erudito a serviço da cultura e da educação
}

Resumo: O músico e dançarino Antônio Carlos Nóbrega usa a prática adquirida durante a trajetória de quase quatro décadas à frente dos palcos para criar um novo espetáculo, em que mostra, através de texto e música, a história das principais danças brasileiras. Nesta entrevista, ele comenta sobre suas influências artísticas, sobre o desafio de unir elementos clássicos e populares nos espetáculos que já criou e sobre o trabalho à frente do Instituto Brincante, criado para disseminar a cultura popular e formar artistas de acordo com o estilo desenvolvido por sua companhia artística.

Palavras-chave: arte, dança, música, cultura popular, educação.
Abstract: The dancer and musician Antonio Carlos Nobrega uses the practice acquired along a trajectory of nearly four decades in the stage to create a new spectacle, in which he shows, through text and music, the history of the main Brazilian dances. In this interview, he talks about his artistic influences, on the challenge of joining classical and popular elements in the shows that he has already created and his work with Brincante Institute, created to spread the popular culture and form artists in the style developed by his artistic company.

Keywords: art, dance, music, popular culture, education.

Filho de médico sanitarista, o estudante de música clássica Antônio Carlos Nóbrega viu-se diante de um mundo novo quando, aos 18 anos, teve contato pela primeira vez com as manifestações de música, arte e dança populares. Estimulado pelo trabalho junto ao Movimento Armorial, organizado por Ariano Suassuna na década de 1970, o jovem músico de classe média descobriu novas formas de expressão artística com o povo do Nordeste.

A herança desse trabalho carregaria pela vida afora - especialmente a partir de 1976, quando o espetáculo A Bandeira do Divino marcaria o início de sua carreira solo. Outros viriam depois, apresentados dentro e fora do Brasil - levando sempre a mistura da técnica e da expressão eruditas com a cultura das tradições populares brasileiras. A experiência sobre os palcos faria com que Antônio e sua esposa, Rosane Almeida, expandissem as atividades para outras esferas artísticas e educativas. Em 1992, nasce o Teatro Brincante, local para ensaios e apresentações que, mais tarde, se tornaria Instituto Brincante, oferecendo cursos para educadores e comunidade, relacionados às técnicas usadas nos espetáculos. As atividades realizadas pelo Instituto fizeram com que ele se tornasse Ponto de Cultura selecionado pelo Ministério da Cultura do Governo Federal. 
Em 2009, Antônio Nóbrega se lança a mais um desafio: sintetizar sua paixão pela dança, e toda a multidisciplinaridade que acompanha seu trabalho, em um único espetáculo, assumindo, sobre o palco, também a função de educador. Em Naturalmente - teoria e jogo de uma dança brasileira, ele aparece não só tocando, mas também conversando com o público, unindo arte e conceito de forma universal. Na entrevista a seguir, Nóbrega fala sobre sua história e sobre como se estruturou para alcançar esse objetivo.

Por Juliana Winkel*

Comunicação \& Educação: Como surgiu seu interesse pela cultura popular? Quais foram seus incentivos?

Antônio Nóbrega: Meu interesse pela cultura popular se deu a partir do contato com Ariano Suassuna, nos primeiros anos da década de 1970, por meio do Quinteto Armorial. Até então, tínhamos um conjunto doméstico em que tocávamos Beatles, temas orquestrais de filmes. Isso dava um contrabalanço ao rigor da academia, onde me preparava para ser concertista.

Antes disso, porém, tive uma história cultural muito rica. Primeiro, por meio de um ótimo professor de violino, Luis Soler. Ele era também um poeta com quem eu podia conversar sobre arte e cultura de maneira mais ampla. Tive um avô escritor que possuía uma biblioteca extraordinária. Ele me deixou, entre outras coisas, a paixão pelos livros. Meu pai, que é muito sensível, também se preocupou em me dar formação musical. Então, quando conheci Ariano, ele veio integrar toda essa corte de pessoas que me instruíram no sentido da arte e cultura em geral, associada a uma boa formação escolar.

Quando comecei de fato a estudar as manifestações do povo, vi que poderia enriquecer muito as possibilidades musicais das apresentações. Ao longo do tempo, plasmei esses conteúdos dos cantadores populares de maneira muito forte. Paralelamente, me interessei também em ler os livros que falavam sobre cultura popular, folclore. Tudo isso foi me dando condições de valorar e compreender a cultura popular. Lembro-me de que muito cedo li, por exemplo, As danças dramáticas, de Mário de Andrade - principalmente a introdução que ele faz aos três volumes da coletânea, e que é um dos ensaios mais completos e talvez ainda o mais importante que se tenha dito sobre as danças brasileiras. Foi escrito há mais de 70 anos e acho que ainda não se fez nada que supere esse trabalho. Depois li outros escritores - Gustavo Barroso, Câmara Cascudo, Sílvio Romero, Arthur Ramos. A leitura disso, associada a uma contínua prática e visitação aos vários grupos e manifestações populares, me deu condições de estar sempre associando a reflexão ao meu próprio trabalho de criador.

* Jornalista, especialista em Gestão da Comunicação pela Escola de Comunicações e Artes da Universidade de São Paulo. E-mail: juwims@ yahoo.com.br.
C\&E: Em seu novo espetáculo, você alia a linguagem cênica da dança com exposições teóricas a respeito de como ela é criada e construída. Como surgiu a ideia de refletir sobre isso no palco?

Antônio Nóbrega: Há muito tempo, eu tinha interesse em tornar públicas algumas considerações que tenho feito em relação a uma dança de matrizes populares. Percebi, ao longo dos anos, que a dança é um dos campos menos 
analisados, menos sintetizados pela cultura popular. Você consegue se lembrar de um grande dançarino que sintetize a cultura brasileira? É possível lembrar de um nome como esse na música, no teatro, mas não o temos na dança.

Porém, relutava em fazer isso dentro de um corpo de espetáculo. Adaptar conteúdo técnico para o público geral, não ligado ao universo da dança, não é muito fácil. Mas, apesar de ter lecionado Danças Brasileiras na universidade, não vejo espaço mais apropriado para isso, ainda, do que o palco, que é meu canal de expressão natural. Então tomei coragem, aplaquei os demônios do medo e me utilizei do recurso de colocar essas considerações entremeando as performances. Para meu espanto, parece que funcionou bastante, porque foi um dos espetáculos em que recebi maior retorno positivo. Isso, de certa forma, me trouxe um sim no sentido de aprofundar ainda mais o trabalho, inclusive aperfeiçoando a própria parte falada dentro do espetáculo.

C\&E: Acredita que a sua experiência como professor foi útil no momento de transmitir esse conhecimento teórico?

Antônio Nóbrega: Fui professor na Unicamp há vinte anos, até 1989. Quando dei aulas, estava começando a organizar e qualificar os conhecimentos, perfazia os primeiros passos na codificação da linguagem e no entendimento da teoria que, agora, está mais bem construída. Acho que tudo é aprendizado, tudo se soma. Se eu for pensar que há vinte anos estava na Unicamp, vinte anos antes disso eu começara a me interessar pelas danças populares. Então, na verdade, tudo se inicia ali, quando pela primeira vez vi a figura de um passista, depois

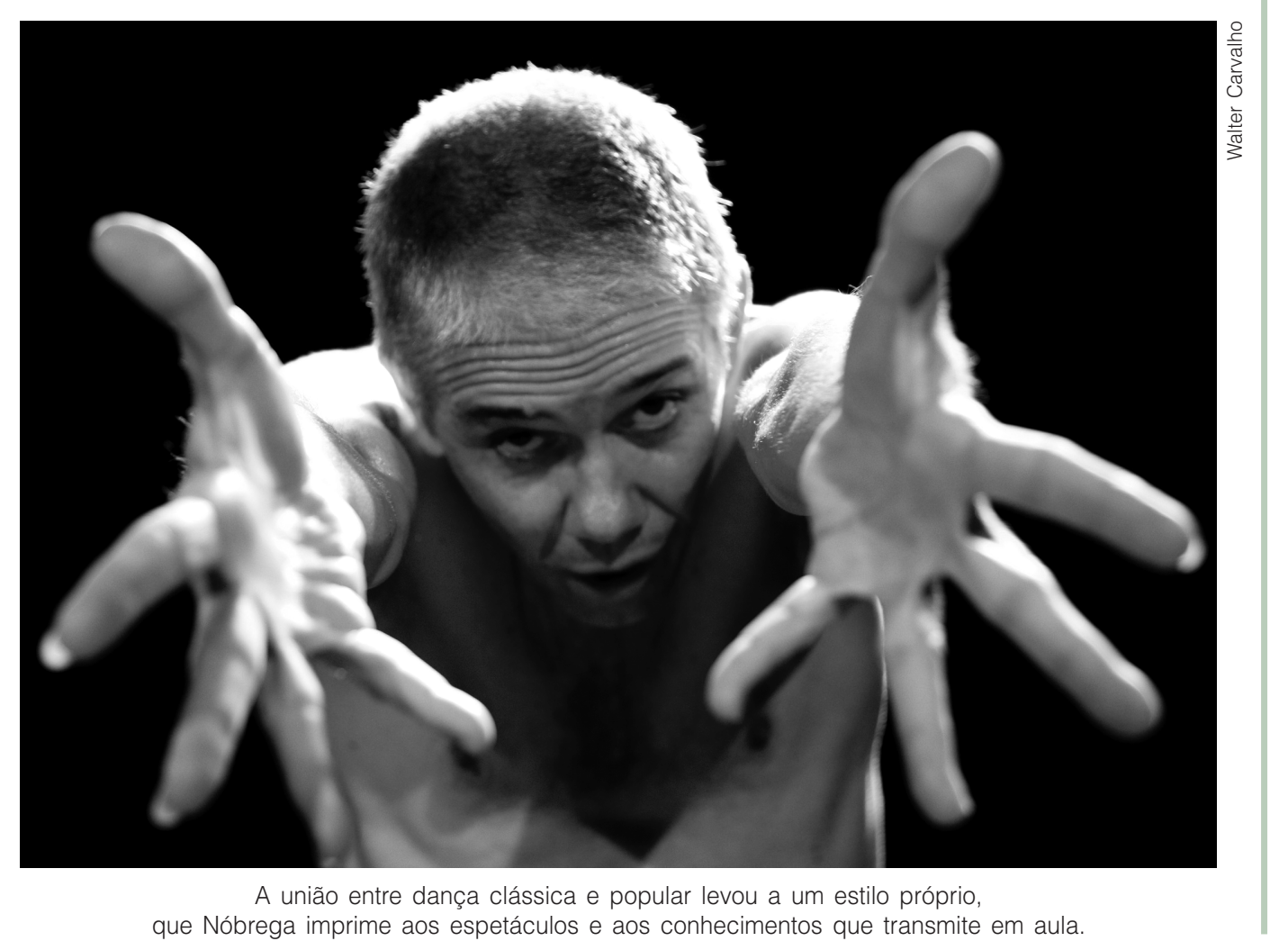


comunicação \& educação • Ano XIV • Número 3 • set/dez 2009

de um dançador de caboclinho, e assim por diante. Aquilo foi me pegando, me seduzindo, e fui assimilando os passos e procedimentos com meu corpo, sem saber aonde ia dar - já que eu tinha 18 anos e não era meu projeto ser dançarino, e sim músico. Mas fui assimilando e incorporando essa cultura corporal dentro de mim e ela foi como que, naturalmente, me possuindo mais do que eu a ela. E essa atitude possessiva dela em relação a mim me obrigou também a uma reflexão que transcendeu os limites da própria dança. Uma reflexão que se amplia em torno da cultura brasileira, justamente da relação em torno desses dois segmentos culturais - a cultura popular e a cultura, vamos chamar, não popular.

C\&E: Você acha que ainda existe uma separação entre a cultura popular e a não popular, como duas vertentes que não podem se juntar em uma mesma obra, por exemplo? Antônio Nóbrega: Normalmente, a cultura popular e seus conteúdos são, de certa forma, compreendidos como circunscritos àquele universo folclórico. Raramente temos um olhar de transcendência para ela. Na música isso já acontece um pouco mais, através de compositores como Villa-Lobos e Radamés Gnattali. Boa parte da tradição da música brasileira já compreendeu os ritmos, o melodismo, o conjunto de características populares que foram absorvidas no plano da composição contemporânea. Porém, no campo da dança, isso ainda ocorre de modo muito discreto, para não dizer que quase não foi feito. Então, trago um pouco à cena essa reflexão de cultura popular versus cultura contemporânea; é possível esse diálogo? Esse é um dos aspectos que o discurso busca atender: lançar a reflexão sobre os conteúdos presentes na cultura popular e sobre como a compreensão desses conteúdos os tornam ativos na dinâmica cultural contemporânea.

E depois, sem dúvida, penso também na questão pedagógica da cultura corporal brasileira. Em que medida esse universo pode se institucionalizar, estar mais presente no cotidiano da nossa cultura corporal? O País possui uma diversidade muito grande de danças e de imaginário corporal. Se isso puder ter uma atualidade maior, pela própria riqueza que esse imaginário encerra, será um valor adquirido pela cultura contemporânea.

C\&E: Existe algum motivo para a dança estar um pouco atrás das outras manifestações nessa compreensão?

Antônio Nóbrega: Acho que sim. Em primeiro lugar, o corpo sempre foi estigmatizado. Nossa herança, principalmente judaico-cristã, sempre estigmatizou o corpo. Isso já deu à cultura corporal um atraso em relação às demais artes. $\mathrm{O}$ corpo é muito mais relacionado, por exemplo, com a entidade do mal do que a música; veja a expressão: "Está com o diabo no corpo!". O corpo que faz determinados trejeitos é quase condenado, visto com desdém. O corpo lascivo presente nas nossas danças negras é sempre visto com muito cuidado. Os batuques raramente chegavam à casa grande, por exemplo.

Uma segunda razão é que, pela maneira como a cultura brasileira se desenvolveu, a partir da segmentação entre a cultura do colonizador e a cultura do colonizado, o intercâmbio entre elas teve, e continua tendo, muito mais 
reticências da classe colonizadora em relação à dança do que em relação à música, à literatura e a outras vertentes da nossa cultura. Um literato tem mais facilidade de compreender a cultura popular, de entender os conteúdos que ele pode assimilar, do que uma pessoa de formação mediana que vá praticar dança e compreenda que naquela dança popular existem também valores que podem ser agregados. Por exemplo, se uma pessoa de classe média brasileira for colocar uma criança para estudar dança, provavelmente entenderá que sua filha - raramente seu filho - deve aprender balé clássico, ou jazz - linguagens já formalizadas que fazem parte do universo da sociedade burguesa em que a classe média se insere. Acreditar que estudar um batuque ou outra dança ligada à cultura popular traga valor é muito difícil. Isso quando existem escolas que ensinam essas danças, o que já é quase impossível. Então, o jovem que sai da academia de dança carrega pouco essa mentalidade. O dançarino brasileiro foi construído para achar que a dança clássica e o jazz são as formas normativas da dança. Já uma pessoa do universo da literatura, e mesmo um músico, acredito, tem uma consciência um pouco mais aberta para entender que existem valores dentro da cultura popular que podem ser tomados e incorporados ao seu trabalho. Então, associo principalmente a esses dois componentes: ao corpo, que sempre era guardador de pecado, e à questão da nossa colonização.

C\&E: Como você vê a popularização da cultura pelos meios de comunicação? Acha que ela contribui ou atrapalha na divulgação das manifestações originais da cultura popular? Antônio Nóbrega: Acredito que hoje as manifestações da cultura popular sejam mais conhecidas. Antigamente, saber o que é uma rabeca era coisa de folclorista. Mas hoje um número maior de pessoas já ouviu falar em Mamulengo, Folia de Reis, Cavalo Marinho. Fazer com que ela chegue a um maior número de pessoas é sempre bom. O problema ocorre quando o eixo de entendimento sai da cultura em si para o dinheiro que ela pode render. Porque essa cultura passa a chegar ao público de forma incompleta na sua essência, o que desmonta também a cadeia de compreensão da cultura. Ela se torna uma arte manca, pobre em significado.

De qualquer forma, não gosto do conceito de cultura "erudita" versus popular. Ele não dá cobertura integral a essas manifestações. A palavra "erudita" é uma palavra que afasta - quando se diz "artista erudito", é como se fosse um artista que está dentro de uma redoma de vidro, com conhecimentos impenetráveis. Em contrapartida, o artista popular ou folclórico é visto como detentor de um conhecimento que não tem muito dinamismo para estar presente no nosso dia a dia cultural. São conceitos que se foram desgastando ao longo do tempo e que não dão mais sentido pleno ao que a gente quer dizer. A cultura que não é popular não é só a cultura erudita, nem a cultura que não é erudita é a popular. E existe aí no meio a cultura de massa, mas esta a gente já sabe mais ou menos o que é.

Acho estranho dizer, por exemplo, "Guimarães Rosa é um escritor erudito". Ora, é um escritor - que, para que você o compreenda, precisa não só saber ler, mas ter intimidade com as palavras, com a leitura. Ser apresentado ao 
comunicação \& educação • Ano XIV • Número 3 • set/dez 2009

romance através de Guimarães Rosa é difícil. Mas o que é mais difícil: uma pessoa iletrada tentar ler qualquer livro, ou a pessoa letrada tentar ler Guimarães Rosa? Para uma pessoa que não sabe ler, pegar qualquer livro ou jornal é mais erudito do que, para quem já sabe ler, pegar um livro de Guimarães Rosa. Podemos pensar o mesmo em relação à música. Para a pessoa que é analfabeta em música, escutar um samba de Nelson Cavaquinho é extremamente erudito: compreender aquele melodismo, aquela letra. Agora, para uma pessoa que compreende Nelson Cavaquinho, escutar Villa-Lobos não é tão difícil assim. Digo isso para mostrar como são voláteis esses conceitos de erudito e popular.

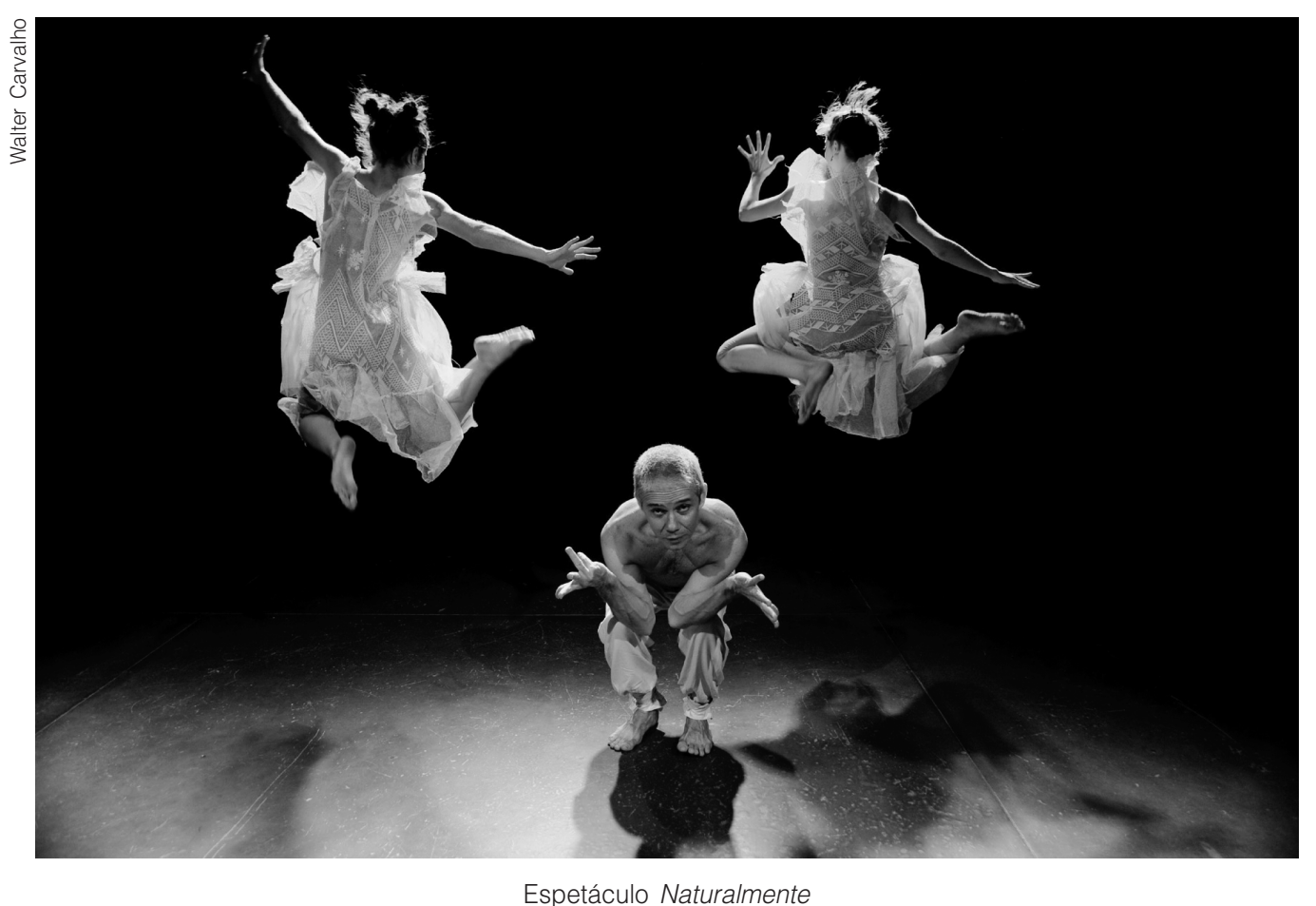

C\&E: Como se pode aproximar esses dois conceitos no entendimento do público, fortalecendo as manifestações populares?

Antônio Nóbrega: Eu acho que o que dará força a esses elementos da cultura popular dentro na nossa cultura contemporânea será a capacidade com que nós, artistas, consigamos tratá-la e apresentá-la. Por exemplo, todo discurso que eu fizer é menor do que as danças que estão presentes no meu espetáculo. Se as danças traduzem o meu pensamento, é isso que vai ter força; é isso que vai levar as pessoas a assistir ao espetáculo, a querer estudar aquela dança, assim como a mídia a mostrá-la. O discurso ajuda, é um coadjuvante. Mas o discurso sem a prática é inoperante. Então, acho que a tarefa é essa: que eu e as outras pessoas, que têm interesse em aprofundar esse segmento, continuemos.

Acredito também que devia haver, nas nossas universidades, pelo menos no curso de Literatura, um período em que as pessoas pudessem ter acesso à Literatura Popular. Não só aos contos, às histórias, mas também às formas poéticas. A poesia popular brasileira possui uma grande riqueza de forma, de gêneros. A 
própria literatura de cordel é um assunto, em si mesmo, da maior abrangência. Infelizmente ainda é um universo muito pouco conhecido, mesmo no Nordeste - assim como tudo que está associado a ele. Quem sabe a constituição de um Reisado, de um Bumba meu boi, de um Guerreiro, de um Congo? É difícil as pessoas entenderem que há, dentro disso, conteúdos ricos para reflexão e para simulação cultural.

Se você estudar um pouco o Bumba meu boi, o Reisado, o Guerreiro, perceberá, por exemplo, muitos elementos que construíram a tragédia grega. Os elementos da tragédia grega são muito próximos daqueles que constituem os nossos espetáculos populares. Se estes espetáculos pudessem dispor de um tempo - cem, duzentos, trezentos anos, e isso Mário de Andrade fala muito bem -, livres de toda interferência externa, eles comporiam formas espetaculares, tais como a tragédia grega, a ópera de Pequim, o teatro de Bali. Numa das falas do meu atual espetáculo, comento sobre as famílias das danças - batuques, cortejos e outros espetáculos populares. Eles são constituídos de música instrumental e cantada, de um universo mítico, de um coro que dança e canta, de atores que vestem máscaras e de textos cantados e recitativos. Ou seja, elementos que se foram desenvolvendo, se sofisticando, se refinando, e vieram dar nessas grandes formas de teatro codificado.

Então, o que cabe a nós fazer? Entender que esses universos podem também se juntar na construção de um teatro brasileiro que, a meu ver, seja mais atuante do que o nosso teatro atual. Digo mais atuante porque o teatro, nesse caso, vem como uma forma de interpretação que une dança, canto e música. Você pode imaginar o que seria assistir a uma tragédia grega em sua forma original, numa arena enorme, com um coro que dançava e cantava, inclusive com a participação do público na catarse. Com o tempo, porém, esse teatro foi ficando cada vez mais textual, principalmente no Ocidente. No Oriente, a união dessas diversas formas artísticas não se perdeu, embora seja hoje muito ligada ao religioso, que por sua vez também se fragilizou. Isso ocorre inclusive no Brasil. Se formos analisar, por exemplo, uma representação da Paixão de Cristo, veremos que nem todos que assistem àquele espetáculo acreditam ou refletem sobre o que estão vendo. Como trazer a presença mítica para o teatro? Esse é o desafio. O universo transcendente do teatro tem que chegar a nós, e um dos caminhos para que isso aconteça é voltar a trabalhar, nele, os elementos artísticos mais amplos.

C\&E: Como vocês procuram explorar esses conceitos dentro do Instituto Brincante?

Antônio Nóbrega: $\mathrm{O}$ que eu e minha equipe levamos ao palco representa a vanguarda daquilo que aplicamos no Brincante ${ }^{1}$. Esse trabalho do espetáculo, educacionalmente, procura se realizar no Instituto. Além do conhecimento prático e técnico, promovemos também uma reflexão a respeito do que é feito artisticamente. Temos, por exemplo, eventos realizados uma vez por mês com a participação de um especialista em diversos campos do saber - geometria, matemática, física, sociologia. Normalmente esses temas têm uma ligação com a situação do Brasil, com as características do País, nossos problemas e dificuldades.
1. Disponível em: <http:// www.teatrobrincante. com.br/>. 
comunicação \& educação • Ano XIV • Número 3 • set/dez 2009

Depois, a partir do que o convidado falou, instauramos uma conversa com o público. Já recebemos Milton Santos, Ariano Suassuna, Cristóvão Buarque.

Os cursos oferecidos, por sua vez, oferecem linguagens artísticas para capacitar pessoas de diversas áreas. A arte do brincante para educadores, por exemplo, é constituído de vários módulos e tem por finalidade instrumentalizar, tanto de forma teórica como prática, esses arte-educadores para seu trabalho nas salas de aula. Os módulos têm, como ponto de partida, referências e matrizes populares no campo da música, da dança, da artesania, da cultura musical infantil e assim por diante. Além desse, temos agora também um outro curso, para jovens brincantes. É um trabalho mais completo que, além de treinar no campo da educação, também fornece conhecimentos no campo da performance, formando uma espécie de artistas-educadores, dando condições para que os educadores possam também se experimentar como artistas. Não são arte-educadores, são artistas-educadores. É um conceito novo que Rosane (Almeida) está desenvolvendo. Estamos terminando a primeira turma agora, muito satisfeitos com os resultados.

C\&E: Seria uma formação voltada não só para artistas, mas também para multiplicadores de conhecimento?

Antônio Nóbrega: Exatamente. Tanto os artistas-educadores quanto os arte-educadores. Como Rosane constatou, isso está inclusive influenciando o mercado no momento de absorver esse pessoal, pelas características que eles têm. Muitas empresas, por exemplo, querem realizar uma vivência com artistas que inclua não só assistir, mas também participar. Esses jovens são preparados

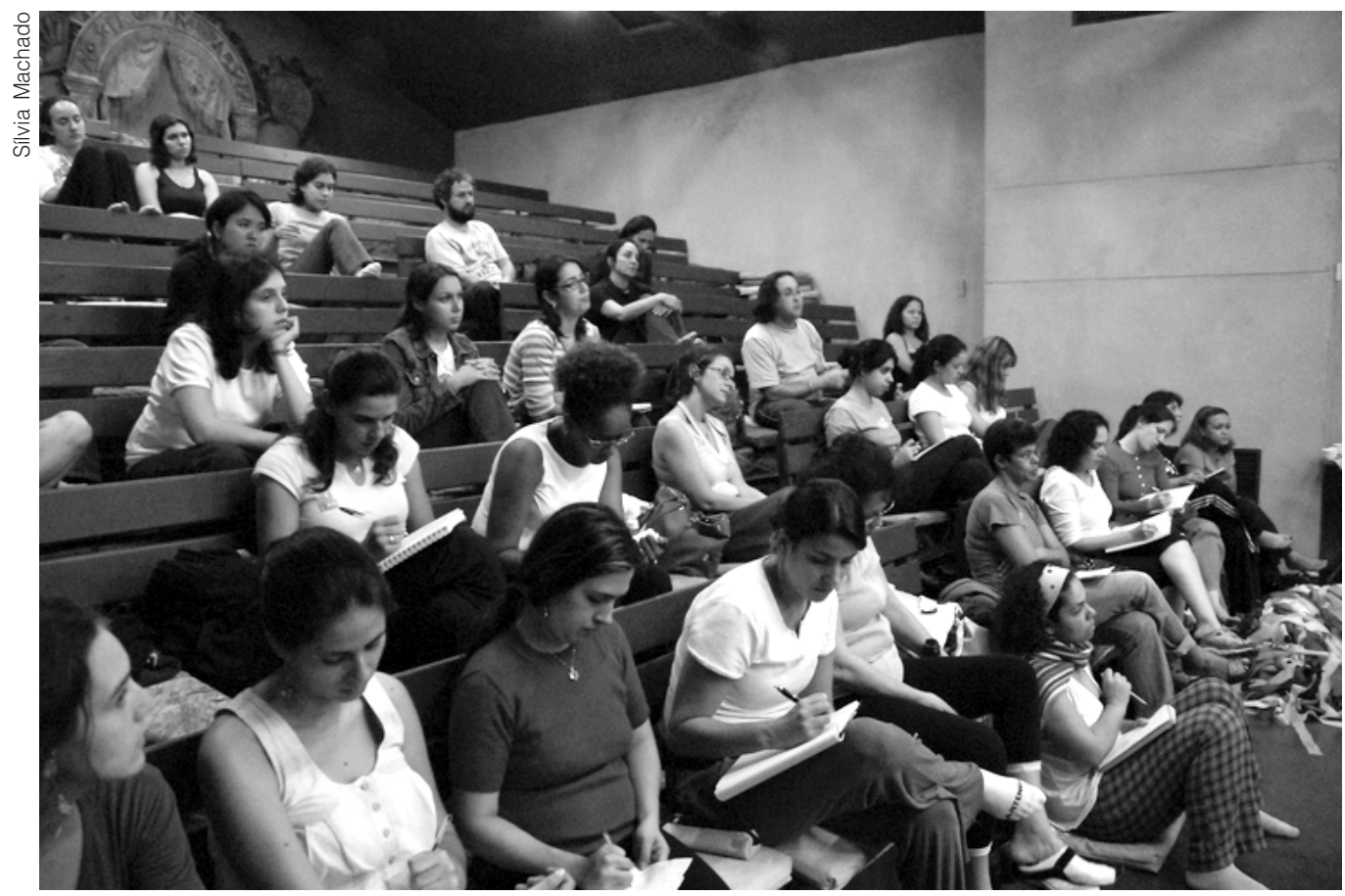

Aula do curso $A$ arte do brincante para educadores 
para atender a essa demanda nascente. Foi uma necessidade intuída por ela a partir dos cursos, da geração de conteúdo nesse universo das humanidades. É uma forma de propiciar a reflexão sobre nosso próprio estar no mundo, sobre o que se pode fazer não só para instrumentalizar as pessoas, mas para ampliar a consciência delas. Dar um pouco mais de anteparo à brutalização do mundo moderno, ao excesso de individualismo, ou seja, a retomada de conceitos que dão um caráter mais humano às nossas vidas.

C\&E: Como você vê o trabalho do Brincante, e o seu próprio trabalho, dentro dessa busca? Antônio Nóbrega: Procuramos incentivar a individualização do trabalho, para que as pessoas possam absorver os conceitos e também recriá-los. Incentivar a criatividade é importante para a cultura da nação. É bonito ver as diferenças regionais e mesmo individuais na maneira como se criam as manifestações populares. O samba de Paulinho da Viola é diferente do samba de Chico Buarque, que é diferente do samba de Caymmi, que é diferente do samba de Adoniran. O chorinho, também, é um legítimo representante da nossa música brasileira, mas está presente em diferentes regiões com distintas colorações. Da mesma forma, um espetáculo de dança é formado por um corpo coletivo e também por vários corpos individuais, cada um metaforizando essa dança de maneira própria. Essa é nossa semeadura. Temos que semear para, a cada dia, colher um pouco. 


\section{Assine a revista Comunicação \& Educação}

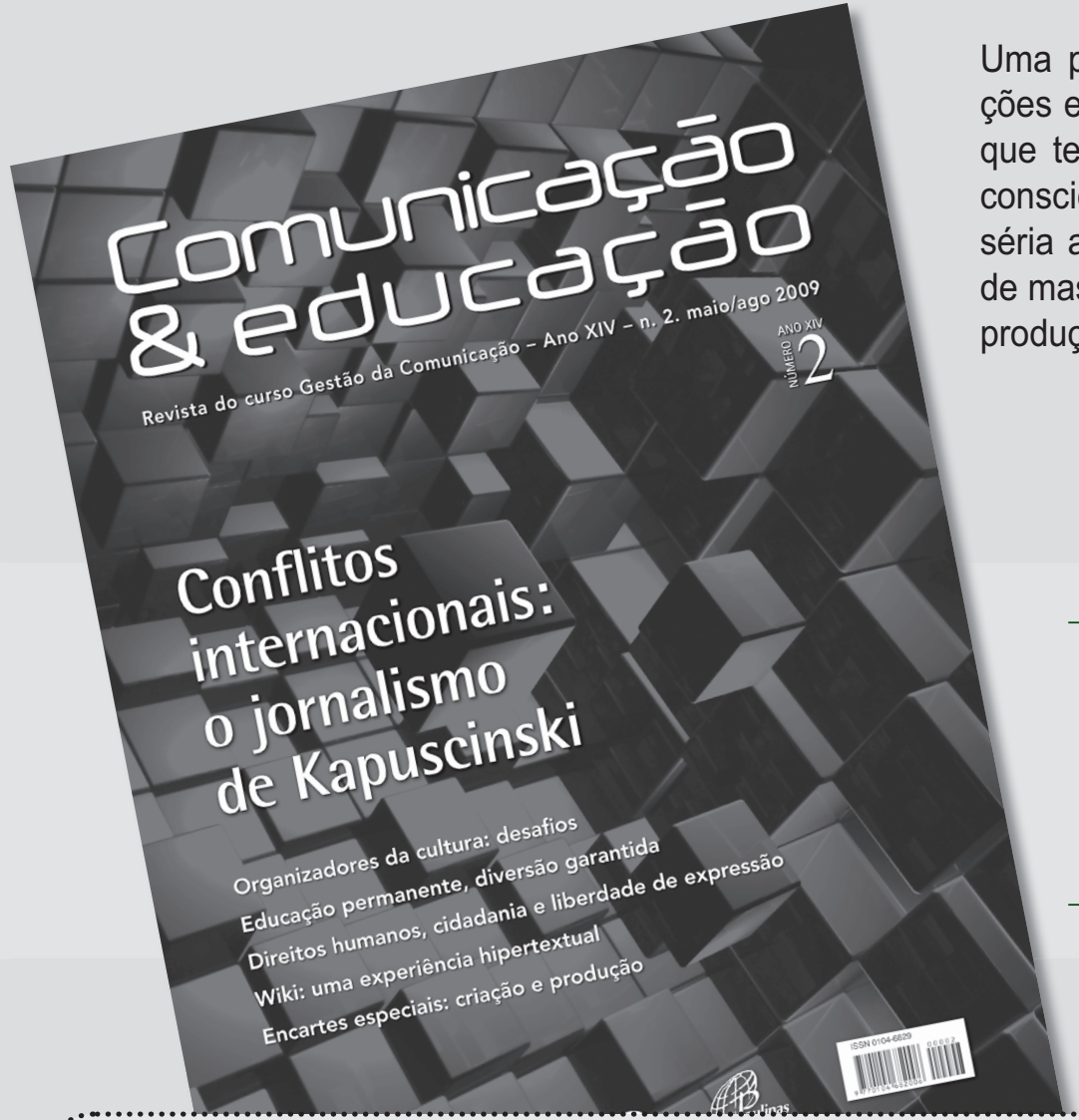

Uma parceria de Paulinas com a Escola de Comunicações e Artes, da Universidade de São Paulo (ECA-USP), que tem por objetivo ajudar a formar profissionais mais conscientes, críticos e interativos, por meio da discussão séria a respeito da natureza dos meios de comunicação de massa, dos direitos da audiência e da crítica estética à produção midiática.

\section{Revista Comunicação \& Educação Periodicidade: quadrimestral}

\section{Ensaios, entrevistas e debates com os maiores especialistas da área auxiliam educadores a incluir em suas práticas novas linguagens e novos recursos pedagógicos.}

\section{ADQUIRA TAMBÉM OS EXEMPLARES AVULSOS!}
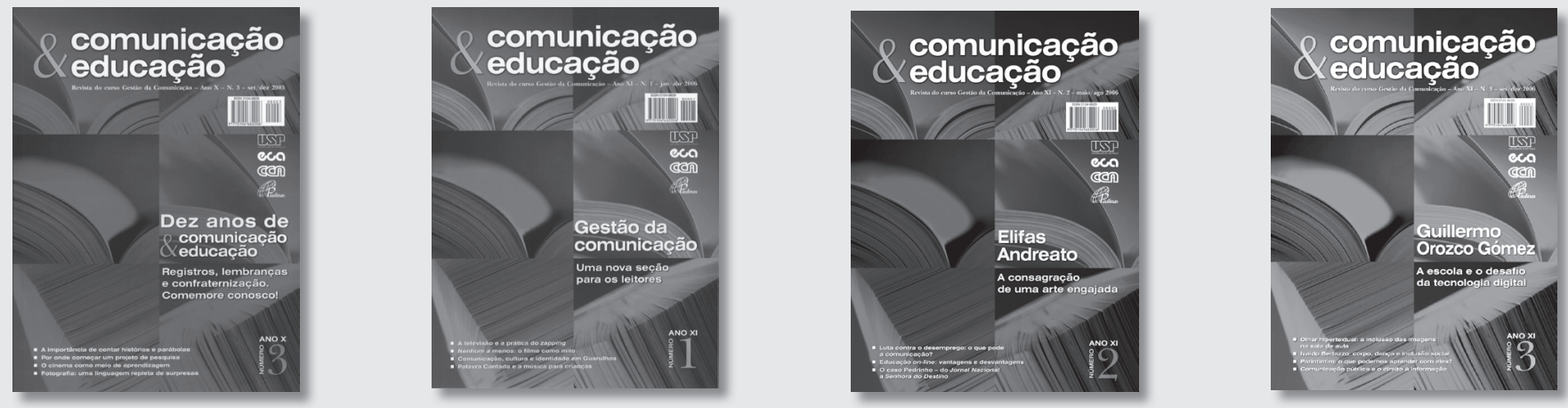

\section{VOCÉ ESCOLHE COMO QUER PAGAR!}

- Cartão de crédito - Visa, Mastercard ou Diners • Boleto bancário

- Depósito bancário identificado • DOC ou transferência bancária

Ligue 0800-7010081 ramal 9448 ou assine

pela livraria virtual Paulinas, acessando www.paulinas.org.br Informações: livirtual@paulinas.com.br 